\title{
Renal cell carcinoma extending through inferior vena cava into right atrium removed with cardiopulmonary bypass
}

\section{support}

Anusua Banerjee, Sandeep Kumar Kar*, Chaitali Sen Dasgupta and Anupam Goswami

Cardiac Anesthesiology, Institute of Postgraduate Medical Education \& Research, India

\section{Case report}

A 68 year old man presented with the complain of painless, gross haematuria since past 1 month. His medical history was remarkable for presence hypertension and Type 2 diabetes mellitus. He had a history of smoking for 10 years with complete abstinence from smoking for last 6 months. He underwent a detailed pre-anaesthetic checkup. A blood haemogram revealed normocytic hypochromic anaemia with a haemoglobin level of $10 \mathrm{gm} / \mathrm{dl}$. Biochemical parameters were significant for a creatinine level of $1.9 \mathrm{mg} / \mathrm{dl}$. Ultrasonography of whole abdomen showed a $3 \times 2.3 \mathrm{~cm}$ space occupying lesion in the left renal mid-pelvic region with evidence of hypoechoic lesion seen in left renal vein extending to inferior vena cava. Magnetic resonance images confirmed the presence of a mass in lower pole of left kidney with nodular component measuring $3.4 \times 2.6 \times 2.1 \mathrm{~cm}$. The medial aspect of the mass was ill-defined. Almost entire length of the vena cava was involved sparing proximal pre-hepatic part and extending to the site of drainage into right atrium. There were no enlarged lymph nodes and the vena caval wall was free. A transthoracic echocardiogram showed tumour infiltration in inferior vena cava and thrombus protruding into right atrium (Figures 1 and 2). Biventricular function was good and there was no evidence of tricuspid regurgitation, pulmonary arterial

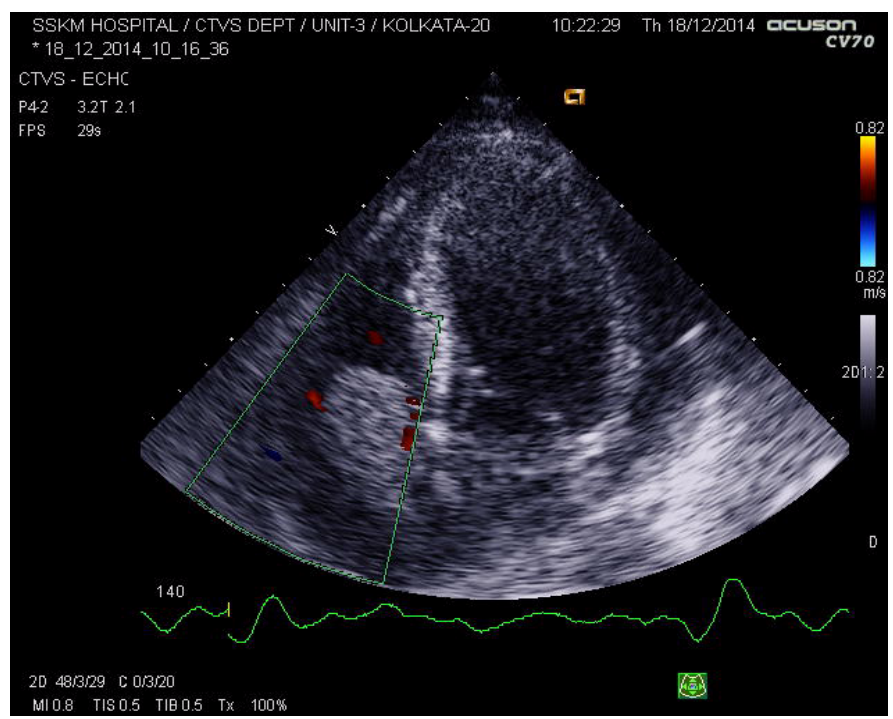

Figure 1. Transthoracic echocardiography showing tumour thrombus protruding from right atrium into right ventricle through tricuspid valve on apical four chamber view. hypertension or pericardial effusion. All the cardiac valves had normal morphology and function.

\section{Management of the case}

A radial arterial cannula was placed in the left hand for continuous invasive blood pressure monitoring before induction of anaesthesia. Intravenous midazolam was given at dose of $0.05 \mathrm{mg} / \mathrm{kg}$ for anxiolysis. Co-induction was done using fentanyl at a dose of $5 \mu / \mathrm{kg}$ and titrated doses of thiopentone sodium. The end point of anaesthetic induction was the loss of eyelash reflex. After an uneventful endotracheal intubation, a central venous catheter was placed in right internal jugular vein under ultrasound guidance. Care was taken not to insert the guide wire beyond $15 \mathrm{~cm}$ and the catheter was fixed on the skin at a distance of $13 \mathrm{~cm}$. A rooftop incision was given for exposure of left kidney and its vascular pedicles and the inferior vena cava. The arteries to the left

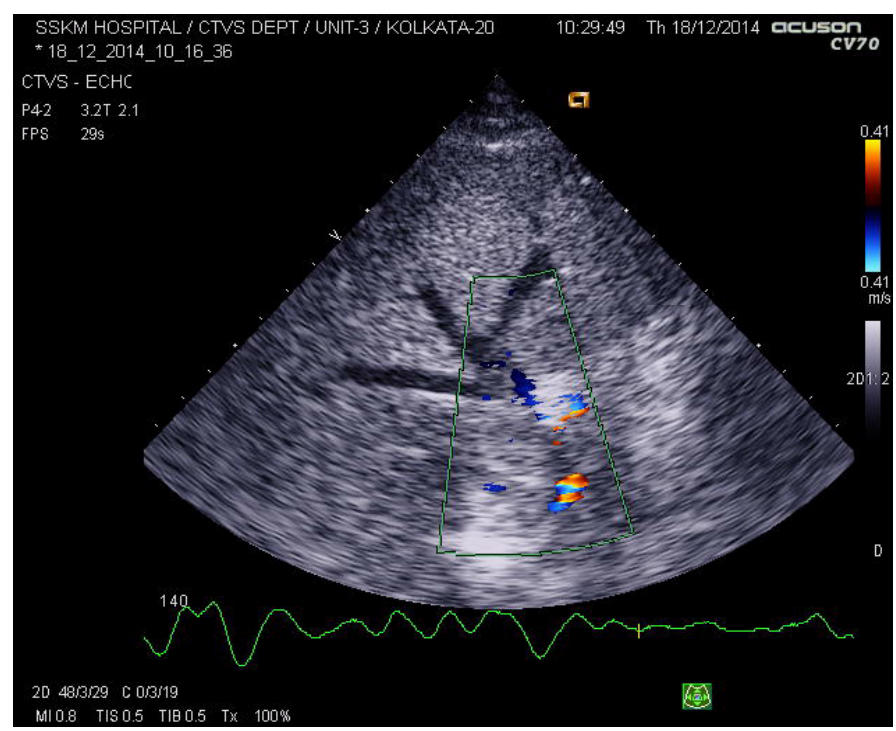

Figure 2. Transthoracic echocardiography image showing dilated hepatic veins and tumour completely obstructing junction of IVC and right atrium.

Correspondence to: Dr. Sandeep Kumar Kar, Assistant Professor, Cardiac Anesthesiology, Institute of Postgraduate Medical Education \&Research, 244 AJC Bose Road Kolkata -700020, India; E-mail: sndpkar@yahoo.co.in

Received: April 18, 2015; Accepted: June 04, 2015; Published: June 07, 2015 


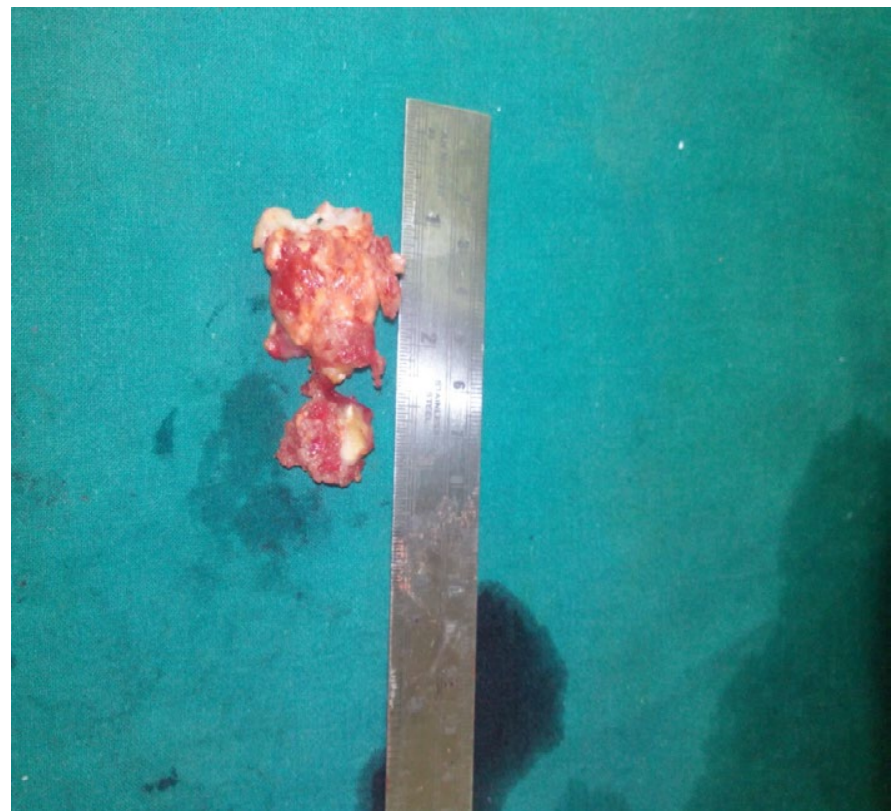

Figure 3. Tumour thrombus after surgical excision.

renal moiety were carefully dissected in cranial to caudal manner and tied off. The main renal vein and tumour thrombus were transected at the level of inferior vena cava and left ureter was identified. A left sided radical nephrectomy was done. A right thoracotomy was done at the level of fourth intercostal space for exposure of right atrium. Systemic heparinisation was done using unfractionated heparin in a dose of $4 \mathrm{mg} /$ $\mathrm{kg}$ to reach an activated clotted time of more than 480 seconds. Superior vena caval cannulation was done using 28 french venous cannula and inferior vena caval cannulation was done beyond the level of palpable thrombus with 32 french venous cannula. Cardiopulmonary bypass was instituted and core temperature was maintained between $32-34^{\circ} \mathrm{C}$. Aortic cross clamping was not done as the tumour mass did not extend into right ventricle and there were no other associated intra-cardiac shunt defects. The right atrium was opened, thrombectomy was done and tumour removed. Blood returning into the right atrium was sucked out with a sucker and discarded to avoid tumor embolization. The tumor was dissected away from the endothelium of the inferior vena cava upto its distal extension. An inferior vena caval reconstruction was done and the right atrium was closed. After de-airing of the heart, weaning from cardiopulmonary bypass was accomplished. Protamine was administered to neutralize residual heparin and decannulation was done. After meticulous surgical hemostasis the chest and abdomen were closed in layers with respective drain in-situ. The perioperative period was uneventful and the patient was discharged on $7^{\text {th }}$ postoperative day.

\section{Discussion of problems encountered in the case}

Prognosis of renal cell carcinoma depends upon a number of factors such as local infiltration of perinephric tissue, lymph node involvement, distant metastases, the pathological stage of the renal cell carcinoma and the presence of vena cava side wall invasion [1]. For tumours extending into intra-cardiac structures, a holistic approach is required involving radiologist, anaesthesiologist, urologist and cardiothoracic surgeon. The use of cardiopulmonary bypass is required for safe and complete excision of renal cell carcinoma extending to the intra-cardiac structures [2]. Some authors have demonstrated lesser intraoperative complication rates when cardiopulmonary bypass was used for level III (retrohepatic intracaval) tumour excision [3]. Controversy exists regarding whether to use deep hypothermic circulatory arrest (DHCA) or to perform the surgery on beating heart. Deep hypothermic circulatory arrest (DHCA) is not usually required unless the tumor thrombus is invading the caval wall or reaches the right ventricle [4]. Deep hypothermic circulatory arrest provides a bloodless surgical field, which minimizes the risk of tumor fragmentation, reduces risk of cellular spreading and subsequent pulmonary embolization and avoids severe haemorrhage from intra and suprahepatic veins. But the use of deep hypothermic circulatory arrest increases the potential for surgical complications like an extended bypass time as a result of rewarming, postoperative bleeding and coagulopathy, and increased neurologic risk [5]. The patients with tumour thrombus obstructing inferior vena cava have extensive venous collaterals. The patients also undergo substantial retroperitoneal dissection for tumour excision. Perioperative coagulopathy in these patients can be life-threatening.

Patients with malignancy are at an increased risk of thrombotic complications manifested either as deep venous thrombosis or pulmonary thromboembolism. Prophylactic use of newer anticoagulants such as bemiparin may show promising results in this group of patients for preventing these life-threatening complications. Bemiparin is a second generation low molecular weight heparin (LMWH) with an excellent pharmacological profile. It has the lowest molecular weight, the longest half-life and the highest anti-Factor Xa/ anti-Factor IIa activity ratio. It is safe for use in special group of patients such as children, elderly, those with renal impairment and congestive heart failure [6]. However, there are no current recommendations for its use in patients with malignancy probably due to paucity of data.

\section{Conclusion}

For safe excision of renal cell carcinoma extending into the right atrium, cardiopulmonary bypass is required. This allows for safe and complete excision of tumour without producing any haemodynamic compromise. Deep hypothermic circulatory arrest has many detrimental effects. In this case its need was obviated because the tumour thrombus did not extend into right ventricle and did not invade inferior vena caval wall.

\section{References}

1. Interact Cardio Vasc Thorac Surg June 1, 2004 vol. 3 no. 2 395-397

2. Chiappini B, Savini C, Marinelli G, Suarez SM, Di Eusanio M, et al. (2002) Cavoatrial tumor thrombus: single-stage surgical approach with profound hypothermia and circulatory arrest, including a review of the literature. J Thorac Cardiovasc Surg 124: 684-688. [Crossref]

3. Welz A, Schmeller N, Schmitz C, Reichart B, Hofstetter A (1997) Resection of hypernephromas with vena caval or right atrial tumor extension using extracorporal circulation and deep hypothermic circulatory arrest: a multidisciplinary approach. Eur J Cardiothorac Surg 12: 127-132. [Crossref]

4. Nesbitt JC, Soltero ER, Dinney CP, Walsh GL, Schrump DS, et al. (1997) Surgical management of renal cell carcinoma with inferior vena cava tumor thrombus. Ann Thorac Surg 63: 1592-1600. [Crossref]

5. Schimmer C, Hillig F, Riedmiller H, Elert O (2004) Surgical treatment of renal cel carcinoma with intravascular extension. Interact Cardiovasc Thorac Surg 3: 395-397. [Crossref]

6. Ciccone MM, Cortese F, Corbo F, Corrales NE, Al-Momen AK, et al. (2014) Bemiparin, an effective and safe low molecular weight heparin: a review. Vascul Pharmacol 62: 32-37. [Crossref]

7. Greene GF, Bissada NK, Madi R (2009) Renal cell carcinoma with caval thrombus extending to the right atrium in a horseshoe kidney: a unique surgical challenge. Can Urol Assoc J 3: E55-57. [Crossref] 
Banerjee A (2015) Renal cell carcinoma extending through inferior vena cava into right atrium removed with cardiopulmonary bypass support

8. Glazer AA, Novick AC (1996) Long-term follow up after surgical treatment for renal cell carcinoma extending into the right atrium. J Urol 155: 448-50. [Crossref]

9. Hermanek P, Schrott KM (1990) Evaluation of the new tumor, nodes and metastases classification of renal cell carcinoma. J Urol 144: 238-241. [Crossref]
10. Babu SC, Mianoni T, Shah PM, Goyal A, Choudhury M, et al. (1998) Malignant renal tumor with extension to the inferior vena cava. Am J Surg 176: 137-139. [Crossref]

11. Chatterjee T, Muller MF, Carrel T, Kaufmann U, Meier B (1997) Images in cardiovascular medicine. Renal cell carcinoma with tumor thrombus extending through the inferior vena cava into the right cardiac cavities. Circulation 96: 2729-2730. [Crossref]

Copyright: (C2015 Banerjee A. This is an open-access article distributed under the terms of the Creative Commons Attribution License, which permits unrestricted use, distribution, and reproduction in any medium, provided the original author and source are credited. 